\title{
Considering the Effect of Motorcyclist Risk Tolerance in Accident Risk Management: A Preliminary Study
}

\author{
Malkhamah, S. ${ }^{1}$, Suparma, L.B. ${ }^{1}$, and da Costa, D.G.N.2*
}

\begin{abstract}
Negative perceptions about accident are usually associated with speeding behavior. However, risk perception has not been considered in accident risk management. It is accepted as a personality matter, thus the number of accidents per year was used as accident risk tolerance indicator. Consequently, due to insufficient measurable indicators, it would be difficult to prevent the increasing speeding behavior. This paper discusses the improvement of accident risk tolerance indicators, i.e. safety factor and margin of safety, and their possible usage in speed management policies. These indicators were built based on the correlation between the results of interview and braking maneuver test. From this combine approach, using aggregated-individual and expert acceptance models, it was found that risk tolerance arose because motorcyclists accepted both the advantages and disadvantages gained from speeding, obtained through their riding frequency, duration of riding and/or accident involvement experienced. However, inappropriate speed due to miss-perception toward braking capability should be avoided. Inversely, an appropriate speed management should consider their travelling expectation.
\end{abstract}

Keywords: Braking capability; margin of safety; risk acceptance and tolerance; safety factor; speed management.

\section{Introduction}

Speeding was indicated as an intentional risk taking behavior since riders have a tendency to exceed their vehicle speed above the regulated speed limit due to various reasons, such as for time saving and sensation seeking purposes-[1-4].

Social-economy advantage was indicated to be primary reason of speeding behaviour. On the other hand, a number of riders who have been involved in slight injuries have a tendency to keep speeding due to their negative perception toward the accident occurrence [5]. They accepted the type of consequences as something usual, or even believe that it was occurring due to bad luck or destiny. A misperception about it could lead them to fatality, because fatal accident probability increases when the speed is high, particularly when the impact speed is greater than $50 \mathrm{~km} / \mathrm{h}$ [6]. However, since not every risky situation has been handled properly, it is thought the produced consequences are accepted as something usual. Consequently, the risk exposure (risky behaviour frequency) and scale of risk would be increased.

\footnotetext{
${ }^{1}$ Department of Civil and Environmental Engineering, Faculty of Engineering, Universitas Gadjah Mada Jl. Grafika No.2 Yogyakarta 55281, INDONESIA

2 Ph.D. student, Department of Civil and Environmental Engineering, Faculty of Engineering, Universitas Gadjah Mada J. Grafika No.2 Yogyakarta 55281, INDONESIA

* Corresponding author: dnoesaku@gmail.com
}

Note: Discussion is expected before November, $1^{\text {st }} 2018$, and will be published in the "Civil Engineering Dimension", volume 21, number 1, March 2019.

Received 01 May 2018; revised 20 August 2018; accepted 06 September 2018
When it occurs, the authorities would need greater efforts and resources to resolve it. Therefore, avoiding crashes and/or the ability in reducing impact speed and the availability of appropriate accident risk mitigations has been latent issues, since the presence of the accident probability and/or consequence indicators as well as risk tolerance indicators and/or criteria are inadequate. In order to avoid crashing, riders need an adequate time and space to react and brake safely, whereby not every rider has a sufficient reaction time and braking capability [7]. It indicates that accident risk analysis should be conducted based on a minimum stopping sight distance (SSD) model. According to AASHTO Edition 2011, it is a sum of reaction and braking distance [8], whilst other studies reported that it is also influenced by down shifting distance [9], air drag [10], etc. Accordingly, the accident risk management strategy should be determined based on its concerned risk indicators and/or risk tolerance, depending on the types of risky conditions and road user characteristics in each study location.

Meanwhile, thus far, the accident risk indicator relies on deceleration rate [11], time to collision [12] and the ratio of sight distance to stopping distance [13]. The deceleration rate has been used to classify potential conflict, whilst time to collision has been used to identify the accident probability. The use of the ratio of sight distance to stopping distance, virtually could describe accident probability more clearly. However, the use of such indicators in accident risk mitigations is very rare. This gap has been bridged by using a minimum margin of safety 
model [14], but since the model was built based on secondary concerned data, it is thought that the more appropriate accident risk and risk tolerance indicators should be further investigated through actual field data, obtained from a number of experiments.

Furthermore, since previous study [15] has found that novice rider could increase their braking capability by up to $2.07 \mathrm{~m} / \mathrm{s}^{2}$ through a short time period of braking manoeuvre training, it is thought that the increased braking capability could trigger speeding behaviour, due to a decreasing in the distance that can be shortened due to the differences in braking capabilities. That is why this paper uses the ratio of available SSD and minimum SSD [9], similar to the ratio of sight distance to stopping distance [13], to be the accident probability indicator, referred to as a safety factor.

In addition, the utilization of hard braking capability has been proven to influence impact speed significantly and end up with a decreasing in fatal crash probability [16]. However, in order to develop comprehensive and sustain risk management programs, further study is required to investigate its correlation with riders risk tolerance. It is hoped that by considering the effect of risk tolerance, the road safety authority could recommend a more appropriate speed limit which reflects not only road geometry and traffic compositions, but also riders' mobility needs and their riding capabilities. This current study is undertaken based on this consideration.

In Indonesia, it is an urgent agenda because although motorcyclist was the most fatal accident victims [17], and their speeding behaviour (exceeding regulated speed limit) in urban areas is a commonly viewed, but it has never been punished [18]. In addition, the fact that $82 \%$ riders usually rode in a range of $50-60 \mathrm{~km} / \mathrm{h}$ almost every day exceed favoured speed due to time saving and sensation seeking [4] confirms that appropriate speed and risk management strategies should be developed.

\section{Design of Study}

Thus far, risk acceptance indicator was considered to be one level of magnitude or type of consequence lower than the tolerable value [19]. However, individual and society perspective on risk tolerance are varied from one person to the other. Individual tolerance could be built through riding experience such as frequency and duration of riding, accident/ incident involvement, familiarity with road, traffic and/or road user characteristics [4,5,20]; as well as the benefit gained from a risky behaviour [3,16, 20]. Sooner or later, it might become society tolerance if the risky conditions and accident consequences are accepted as something usual, or even a destiny. Therefore, since many risk exposure such as speeding behaviour, virtually, could be intervened and managed, it is hoped that the result of this study can be used in accident risk management based on riders risk tolerance, so that it is realized that the availability of risk acceptance criteria is a mandatory and urgent need.

As previously mentioned, the aim of this paper is to describe risk tolerance using riders' positive and negative perceptions about speeding consequences. The positive perception is related to potential socialeconomy advantages gained from speeding, whilst the negative perception was described based on their accident involvement experiences, predicted using safety factor and minimum margin of safety models. The safety factor is defined as the ratio of available SSD to minimum SSD, where the available SSD is associated with risky conditions such as a critical crossing gap acceptance at an un-signalized intersection. The minimum SSD was determined by taking into account the effect of downshifting and hard braking deceleration rate because in the preliminary study it was found that the reduced speed obtained during downshifting influence the braking distance and the impact speed significantly [21]. The margin of safety is defined as the distance that can be shortened due to differences in braking capabilities.

The data were collected through a combination of experimental and interview method, where the same monitored participants involved in braking distance test were asked to fulfil questionnaire. The braking distance test was conducted on a dry and level closed circuit course, whilst the questionnaire was taken right after each participant finished their braking distance maneuver test. This strategy makes the authors able to compare the data obtained from experiment and those from the interview.

A number of 141 motorcyclists from a wide range of ages, riding experience, and educations weresuccessfully recruited. Motorcyclists was the monitored riders because they contribute the highest portion of fatalities and/or severe injuries (the abbreviated injury scale (AIS) score > 3) [22]. They are briefed about the aim of the test and asked to apply a hard braking as soon as they saw a stop sign. If they agree to participate then their motorcycle's physical conditions, such as the brake system, braking lamp and tire condition, was checked to ensure that the vehicle is worth to be used in the test. The use of their own motorcyclist was based on a consideration that they could apply their maximum braking capabilities due to their familiarity with the vehicle conditions, particularly its braking system's performance. 
Each participant was asked to conduct 2 to 3 sessions of the test. First, in order to obtain an engine braking deceleration rate, they were asked to travel in their daily favoured speed and then stop accelerating immediately without braking, when crossing the downshifting line. The speed was measured twice by using a speed gun, i.e. at approximately $20 \mathrm{~m}$ before and after the downshifting line, whilst the elapsed time from point to point marked, i.e. as far as $20 \mathrm{~m}$, was measured by using a stopwatch. Accordingly, each participant was asked to achieve their daily favoured speed at about $25 \mathrm{~m}$ before the first measurement point (downshifting line). Then, the engine braking deceleration rate $\left(a_{1}\right.$, $\mathrm{m} / \mathrm{s}^{2}$ ) was calculated using Equation (1).

$a_{1}=0.278 \frac{\left(V_{1}-V_{0}\right)}{t}$

Where $V_{o}$ is approaching speedbefore crossing the downshifting line $(\mathrm{km} / \mathrm{h}), V_{1}$ is speed at the point of $20 \mathrm{~m}$ after crossing the downshifting line $(\mathrm{km} / \mathrm{h}), t$ is average travel time from point to point marked (s).

In the second test, the position of the stop sign was dynamically determined based on the previously chosen speed. Each participant was asked to travel at the same previous speed and apply their maximum braking capability (hard braking) as soon as they saw a stop sign. The position of the stop sign is approximately the same with the predicted stopping line, which was previously simulated in laboratory work, based on the predicted speed range of 40 to $80 \mathrm{~km} / \mathrm{h}$, a minimum reaction time of $1 \mathrm{~s}$ [8] and a braking deceleration rate of $6 \mathrm{~m} / \mathrm{s}^{2}$ [11].

In this particular case, if he/she passed through the stopping line, then it is thought that the produced braking force is not optimal. Therefore, he/she was investigated, i.e. about the usage of rear and front brakes. If it is found that he/she apply only rear brake then he/she is asked to repeat the braking distance test by using both rear and front brake consecutively and/or concurrently. Therefore, they need a little more time to practice it before reparticipate in the braking manoeuvre test. This scenario was conducted based on the findings of previous studies [7,15] which reported that braking capability could be increased technically. It may well also being influenced by their steering control capability or level of courage (consider not to fall during the braking manoeuvre).

The braking deceleration rate $\left(a_{2}\right)$ then was determined based on braking distance (the distance that is needed to completely stop from the instant the brakes were actually applied) and the vehicle speed before braking $\left(V_{1}, \mathrm{~km} / \mathrm{h}\right)$ using Equation (2).

$a_{2}=0.039 \frac{V_{1}{ }^{2}}{S_{b}}$ where $S_{b}$ is braking distance (m). Equation (2) was built based on a consideration that the braking deceleration rate is constant in a particular zone [23]. Therefore, based on the same assumption, the impact speed $\left(V_{2}\right)$ along the braking distance path could be determined using Equation (3).

$S=\frac{V_{1}{ }^{2}-V_{2}{ }^{2}}{a_{2}}$, or $V_{2}=\sqrt{V_{1}^{2}-2 a_{2} S}$

In order to understand the reason of speeding behaviour, this paper uses the ratio of available SSD to minimum SSD (safety factor, SF) and impact speed as the accident risk indicator. The lower the $\mathrm{SF}$, the higher the accident probability; and the higher the braking deceleration rate, the lower the impact speed. In this particular case, for an unsignalised intersection, the available SSD is defined as the mean critical crossing gap acceptance [9]. Similar analogies could be used when determining the presence of various hazardous objects and/or conditions on the roadway. Subsequently, as previously mentioned, since the effect of engine and hard braking deceleration rates was takeninto account, a minimum SSD was determined using Equation (4).

$\min S S D=0.278\left(V_{\mathrm{o}} * t_{1}-\frac{1}{2} a_{1} \cdot t_{1}{ }^{2}\right)+0.039 \frac{V_{1}{ }^{2}}{a_{2}}$

Equation (4) shows that min SSD was a sum of reaction and downshifting distance $\left[0.278\left(V_{\mathrm{o}} * t-\right.\right.$ $\left.\left.\frac{1}{2} a_{1} \cdot t^{2}\right)\right]$ and braking distance $\left(0.039 \frac{V_{1}^{2}}{a_{2}}\right)$. The reaction and downshifting time, i.e. since the stop sign was given until the rear brake was flashed on, was measured by using both stopwatch and camera. Subsequently, the SF was used to determine the minimum margin of safety that indicate the minimum effort needed to avoid a crash and/or fatal crash, which could be calculated by using Equation (5).

Margin of safety $(M S)=$ safety factor -1

Since AASHTO has recommended the use of a reaction time of $1 \mathrm{~s}$, instead of $2.5 \mathrm{~s}$, for determining the min SSD, consequently, this minimum margin of safety could also be built based on the differences in braking capability. Therefore, the awareness of the differences in the produced minimum SSDs and/or distance that can be shortened due to the difference in braking capability could trigger rider perception about speeding consequences. This assumption is in accord with previous study which stated that risky driving (speeding behavior) is personality matters [24]. That is why riders' perception toward their reaction and braking capabilities as well as about their hazard detection abilities and their level of familiarity with traffic, road user, vehicle, road and road environment conditions are required to be investigated using questionnaires. 
However, the dynamic interaction between personality and specific risky situation on a roadway should be further examined. It is assumed that individual tolerance might reflect aggregated-individual tolerance and the aggregated-individual tolerance could be both defined and explained by technical (expert) models. It is hoped that by using this combination of empirical and normative approaches [25], the obtained result could be used to recommend more appropriate speed management strategy and/or techniques.

\section{Results and Discussion}

\section{Reaction Time and Braking Capability}

In normal conditions, a reaction time of $2.5 \mathrm{~s}$ and a braking deceleration rate of $3.4 \mathrm{~m} / \mathrm{s}^{2}$ were used to determine SSD, but in a particular condition, although some previous studies found that a reaction time could be less than $1 \mathrm{~s}$, such as $0.66 \mathrm{~s}$ or $0.67 \mathrm{~s}$; AASHTO has recommended the use of a reaction time of $1,64 \mathrm{~s}$ for a minimum SSD. This phenomenon indicates that there is a margin of safety which could be used as an accident risk tolerance criterion. Accordingly, since braking capability could also greater than $4.5 \mathrm{~m} / \mathrm{s}^{2}$, such as $6 \mathrm{~m} / \mathrm{s}^{2}$ [11] or $7,72 \mathrm{~m} / \mathrm{s}^{2}$ [15] and even $9.7 \mathrm{~m} / \mathrm{s}^{2}$ [23], accident risk criteria should also be considered based on various riders braking capabilities.

Before breaking, riders usually decrease their vehicle speed by downshifting instantly. However, according to AASHTO Editions 2004 and 2011, they usually need a perception reaction time around $1,64 \mathrm{~s}$. Besides decreasing the speed, during this time, the rider (particularly inexperienced rider) has an opportunity to utilize their maximum braking capabilities. The result of Pearson correlation of product moment (R) test showed that although the correlation between the braking capability and reaction time was poor, i.e. -0.32 , but statistically it is significant.

Further, from the statistic distribution of riders braking capabilities, it could be inferred that braking deceleration rate could be classified as below average (less than M-1SD, i.e. $4.63 \mathrm{~m} / \mathrm{s}^{2}$, mean 3.9), moderate (M-1SD $\left(4.63 \mathrm{~m} / \mathrm{s}^{2}\right) \leq \mathrm{X} \leq \mathrm{M}+1 \mathrm{SD}\left(8.87 \mathrm{~m} / \mathrm{s}^{2}\right)$ and above average (greater than $8.87 \mathrm{~m} / \mathrm{s}^{2}$, mean 10.7 ). The overall meanbraking capability was $6.57 \mathrm{~m} / \mathrm{s}^{2}$ (max. 12.68), greater than $5.65 \mathrm{~m} / \mathrm{s}^{2}$ (without ABS) but less than $7.72 \mathrm{~m} / \mathrm{s}^{2}$ (with ABS) [15]. The result is interesting because the mean braking deceleration rate of non-ABS riders in above average braking capability much greater than the ABS one, i.e. 8.15 $\mathrm{m} / \mathrm{s}^{2}$ [15]. Besides which, it was also found that from $86 \%$ of riders who believe that their braking capability above average, only very few riders (17\%) could apply a high level of braking capability, much less than the number of speeders (riders with a daily favoured speed greater than $60 \mathrm{~km} / \mathrm{h}$ ), i.e. $42 \%$. However, the result indicates that, virtually, the rider has realized that braking capability played important role in accident occurrence.

Furthermore, it was also found the average vehicle deceleration during downshifting at around $1 \mathrm{~s}$ was almost $5 \mathrm{~km} / \mathrm{h}$, so that the minimum SSDs for various speed choices and braking capabilities could be seen in Table 1. It shows that the reduced speed due to downshifting and hard braking capability play an important role in accident probability.

Table 1 The Distance that can be Shortened due to Differences in Braking Capability

\begin{tabular}{ccccccc}
\hline \multicolumn{3}{c}{ Speed Min SSDs* } & \multicolumn{4}{c}{ Shortened Distance (ShD) } \\
\hline $\mathrm{V}_{0}$ & 1 & 2 & 3 & $1-2$ & $2-3$ & $1-3$ \\
80 & 71,9 & 49,1 & 36,2 & 22,8 & 12,9 & 35,7 \\
70 & 55,9 & 38,8 & 29,1 & 17,1 & 9,70 & 26,8 \\
60 & 41,9 & 29,6 & 22,7 & 11,4 & 5,80 & 17,2 \\
50 & 29,9 & 21,7 & 17,1 & 7,40 & 3,80 & 11,2 \\
\hline
\end{tabular}

*1= below average braking capability: $3.9 \mathrm{~m} / \mathrm{s}^{2}, 2=$ moderate: $6.57 \mathrm{~m} / \mathrm{s}^{2}, 3=$ above average: $10.7 \mathrm{~m} / \mathrm{s}^{2}$

$* *=\min$ SSDs differences between rider 1 and 2 , and so on

It can be seen that when the speed was below 60 $\mathrm{km} / \mathrm{h}$, the shortened distance between moderate and above average braking capabilities was around 3.8 to $5.8 \mathrm{~m}$, similar with the chosen distance headway on the roadway. Understandable, the awareness of it, obtained from riding experience (riding frequency and/or duration of riding) [4], could trigger the riders' perception of accident probability and/or its possible consequences, confirmed to Knight et al. [5].

\section{Accident Probability and Consequence Indica- tors}

Speeding in urban road networks, particularly when passing through an un-signalised intersection at speed $\geq 60 \mathrm{~km} / \mathrm{h}$, is a risky behaviour because Table 2 shows that, for a speed $60 \mathrm{~km} / \mathrm{h}$, only riders in the moderate and above average braking capability categories has a possibility to avoid crashed when an imaginary hazardous object suddenly arose at the distance of $20 \mathrm{~m}$ on ahead (available SSD).

This conclusion has been drawn due to the finding of previous study reported that novice rider could increase their mean hard braking deceleration rate by $2.07 \mathrm{~m} / \mathrm{s}^{2}$ (Std. Dev. 2.12, max. 4.09) [15]. In this particular case, from Table 2 it can be seen that when driving at speed $60 \mathrm{~km} / \mathrm{h}$, riders with moderate and above average capability should increase their braking capability by around $5.93 \mathrm{~m} / \mathrm{s}^{2}$ (12.68-6.75)) and $1.98 \mathrm{~m} / \mathrm{s}^{2}(12.68-10.7)$ respectively because a min 
SSD of almost $21 \mathrm{~m}$ (SF closer to 1.0) could be achieved by using the obtained maximum hard braking deceleration, i.e. $12.68 \mathrm{~m} / \mathrm{s}^{2}$.

Table 2 Accident Risk Situation due to Speed Choices Difference

\begin{tabular}{cccccccccc}
\hline $\begin{array}{c}\text { Speed } \\
(\mathrm{km} / \mathrm{h})\end{array}$ & \multicolumn{3}{c}{ Min SSDs } & \multicolumn{4}{c}{ Safety Factor (SF) Margin of Safety $(M S)$} \\
\hline $\mathrm{V}_{0}$ & 1 & 2 & 3 & 1 & 2 & 3 & 1 & 2 & 3 \\
\hline 80 & 71,9 & 49,1 & 36,2 & 0,28 & 0,41 & 0,55 & $-0,72$ & $-0,59$ & $-0,45$ \\
70 & 55,9 & 38,8 & 29,1 & 0,36 & 0,52 & 0,69 & $-0,64$ & $-0,48$ & $-0,31$ \\
60 & 41,9 & 29,6 & 22,7 & 0,48 & 0,67 & 0,88 & $-0,52$ & $-0,33$ & $-0,12$ \\
50 & 29,9 & 21,7 & 17,1 & 0,67 & 0,92 & 1,17 & $-0,33$ & $-0,08$ & 0,17 \\
\hline
\end{tabular}

Understandable, if the speed is above $60 \mathrm{~km} / \mathrm{h}$, then the effort needed to be increased is much greater, which might be very difficult to be achieved because it has to be increased exponentially. It strongly indicates that: 1) a miss-perception, and/or over confidence in braking capability could trigger inappropriate speed chosen, 2) it is worth to consider the effect of braking capability in speed management devices. This paper shows that safety factor which is reflected in the distance that can be shortened due to the differences in braking capabilitymodel could be used to describe the accident probability, whilst the minimum margin of safety can be used to determine more appropriate accident risk management strategies and/or techniques required to avoid crash and/or fatal crash probability.

However, such models could not be used to clearly explain the correlation between accident consequences and risk perception and/or risky behaviour. Accordingly, since in the safe system approach [26], generally, an acceptable risk was associated with the zero fatality philosophy, so that accident risk consequences was explained using predicted impact speed, described in the following sentences.

WHO reported that a decreasing in impact speed of $10 \mathrm{~km} / \mathrm{h}$ could reduce the fatal crash probability, by up to $20 \%$ [6]. Since the impact speed was influenced by vehicle speed before braking and braking deceleration rate, the effect of engine braking force to vehicle speed before braking was investigated. The result showed that, when the duration of downshifting was around $1 \mathrm{~s}$, the approaching speed decreased by approximately $5 \mathrm{~km} / \mathrm{h}$ (the engine braking deceleration rate was around $1.29 \mathrm{~m} / \mathrm{s}^{2}$ (Std. Dev. 0.29). The effect of reduced speed due to downshifting to braking distance and impact speed then was tested. From the chi-squared test it was found that a reduced speed of $5 \mathrm{~km} / \mathrm{h}$ significantly influenced not only the braking distance, but also impact speed, as can be seen in the following Table 3.

Moreover, Figure. 1 shows that braking capability much influence braking distance and impact speed.
It strongly confirms the answers of respondents who was the monitored rider who participated in braking manoeuvre test, i.e. that braking capability was believed to be the primary factor that influence speed choice (speeding behaviour), in accord with previous works which stated that braking capability played important role in accident occurrence $[6,26]$.

Table 3. The Effect of Reduced Speed due to Downshifting to Braking Distance and Impact Speed

\begin{tabular}{lcc}
\hline \multicolumn{1}{c}{ Description } & \multicolumn{2}{c}{ Chi-square $\left(\mathrm{x}^{2}\right)$} \\
\cline { 2 - 3 } & Calculation & Standard \\
\hline $\begin{array}{l}\text { The effect of a reduced speed } \\
\text { due to downshifting to braking }\end{array}$ & 17.704 & 15.507 \\
$\begin{array}{l}\text { distance } \\
\begin{array}{l}\text { The effect of a reduced speed } \\
\text { due to downshifting to impact } \\
\text { speed }\end{array}\end{array}$ & 45.09 & 15.507 \\
\hline
\end{tabular}

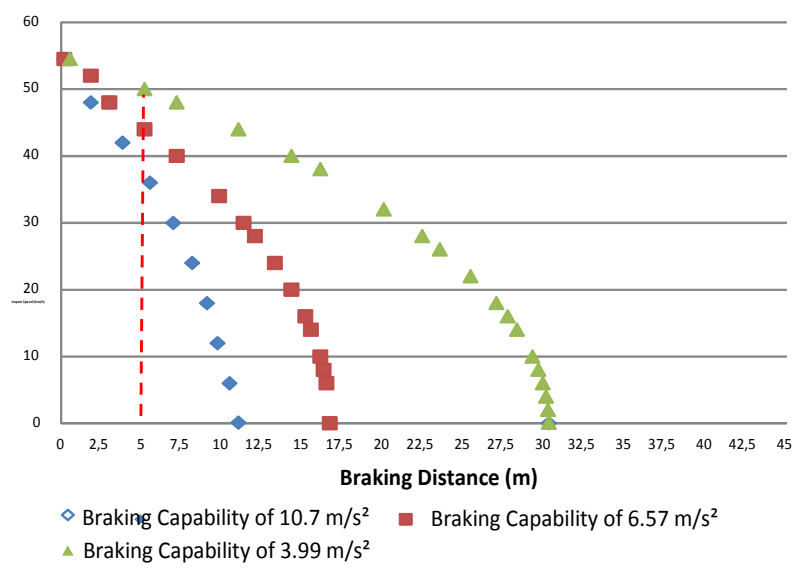

Figure 1 Predicted Impact Speed along Braking Distance Path for Various Braking Capability Categories

Furthermore, when compared with the curve correlation between fatal crash probability and impact speed [6], Figure1 showed that if there was a hazardous object at a distance of $20 \mathrm{~m}$ ahead [9] and the minimum perception reaction time for all types of riders was $1 \mathrm{~s}$ [8], an initial and approaching speed of 60 and $55 \mathrm{~km} / \mathrm{h}$ respectively; the perception reaction distance would be at approximately $16 \mathrm{~m}$, so that the impact speed for riders in above average, moderate and below average braking capabilities categories, at a braking distance of $4 \mathrm{~m}$, would be around 35,42 and $50 \mathrm{~km} / \mathrm{h}$ respectively, as can be seen in Figure 1. Consequently, according to [6], the probability of riders in below average braking capability category to be involved in fatal crash is $80 \%$.

\section{Risk Tolerance}

Perception about accident risk and its tolerable indicators usually was built based on riding experience, accident involvement experience and/or rider's expectation. Thus far, risk perception was 
usually collected by using the interview toward one self-reported model, where the correlation among variables behind it was generally determined using structural equation model [27]. However, the perception could be wrong. For example: most speeders believed that their braking capabilities are above average. Therefore, this paper offers a combination method, i.e. by using not only the result of the interview, but also minimum margin of safety, required due to the differences in braking capability. From the braking manoeuvre test it was found that only $17 \%$ of $56 \%$ of riders, who believe that their braking capability were above average, could achieve a level of braking capabilities required to avoid serious injury crashes recommended by Malkhamah et al. [11], i.e. greater than $6 \mathrm{~m} / \mathrm{s}^{2}$. It is interesting because almost every day most participants admitted that they usually exceed their daily favoured speed due to believing in their braking capability.

Subsequently, as previously mentioned, riders should increase their braking ability exponentially. However, accordingto WHO [6], accident risk management was built based on zero fatality philosophy, instead of zero accident. Hence, based on Figure 1, it implies that a minimum braking capability of $6.57 \mathrm{~m} / \mathrm{s}^{2}$ is a mandatory requirement because with the given impact speed of $42 \mathrm{~km} / \mathrm{h}$, the fatal crash probability of $60 \%$ might be tolerable because the possible head injury criterion (HIC) is less than its tolerable limit, i.e. $43 \mathrm{~km} / \mathrm{h}$ [28].

Consequently, only riders in below average braking capability should improve their braking skill. This could be systematically managed (educated, trained and tested simultaneously) by improving the driving licensing mechanism. Driving license criteria should be added with the required minimum braking deceleration rate, referred to such fatal crash probability level of acceptance. The effect of risk tolerance to accident risk might be adopted not only in traffic safety campaign material, but also into the accident risk management criteria because, thus far, the accident risk tolerance indicator was considered to be the ratio of victims per regular time period and/or the level of injury level per accident which could not be intervened appropriately.

However, these findings strongly indicate that, in order to understand and explain determinant variables behind the speeding behaviour, the use of aggregated-individual acceptance approach would be better if it is combined with technical (expert acceptance) model because it would minimize the subjectivity. This understanding point of view achievement, i.e. that perception and braking capability could be intervened, might help the authorities to recommend more appropriate accident risk management devices such as speed limit, risk perceptions and riding skill (braking capability) as well as to provide better traffic campaign materials and law enforcement.

Those kinds of mitigations might be undertaken through not only socialization or education, but also an intensive training, as a complementary system. Accordingly, in order to build psychological effect, an initial approach has been undertaken by asking students to observe the post crashed handled in the hospital's intensive care unit rooms. The observation result was presented in the classroom. The effect was very interesting because almost all participated students admitted that the medical atmospheric in the operation room scares them so that they intended to stop speeding and/or taking unnecessary risk while driving. It indicates that a changing in risk awareness or acceptance could be built by involving riders and/or potential riders in such uncomfortable situation.

This type of preventive approach, of course, should be further explored, particularly toward its possible negative consequence, such as traumatic effect, to young potential riders. The use of these education, engineering, and enforcement approaches confirms to what has been recommended by some previous researcher $[27,29,30]$.

However, it is noteworthy that, virtually, a tolerance might be allowed only if the unfortune situation is hard to be intervened, instead of a limitation or lack in technical approach and/or modelling. That is why breaking the speed limit, or a fatal crash occurrence due to speeding which was considered to be a destiny, or neglecting braking capability and risk tolerance in speed limit determination, should not be tolerated.

\section{Conclusion}

The conclusions that could be drawn are:

- Speeding could be considered to be an intentional risk taking behaviour since riders accepted the advantages and tolerated the possible dis-advantages gained onit, in accord with references[1$3,20]$.

- Braking capability, particularly due to a combination between the engine and braking deceleration rates, played an important role in accident risk analysis because the braking distance and impact speed could be reduced significantly, as previously predicted in a previous preliminary study [16].

- The awareness of the distance that can be shortened due to differences in those braking 
capabilities could trigger negative and positive perception about speeding consequences because the lower the hazard presented during their riding experience, the more they are willing to engage in risky behaviour, similar with the finding of previous studies [5,31,32].

- Perception could be wrong. A misperceptionin braking capabilities might end up inappropriate speed chosen and increasing in both accident involvement probability and severity level. Therefore, perceptions should be tested, particularly a measurable perception, because this study found that the use of a combination between aggregateindividual and expert acceptance approaches, in accordance with Lacasse [19], could better describe the accuracy of rider's perception about their braking capability which is believed to be the triggering variable of their speeding behavior.

- Both perception and braking capability could be improved through not only socialization or education, but also an intensive training, as a complementary system. This kind of comprehensive and integrated mitigation strategy much possible being undertaken during the driving licensing process.

- Based on the safety factor and/or margin of safety model and zero fatality philosophy, an appropriate accident risk management could be determined more objectively. Consequently, it is worth to consider the effect of motorcyclist braking capability, risk tolerance as well as their expectation in the accident risk management devices.

\section{Acknowledgement}

The authors would like to thank the Ministry of Research, Technology and Higher Education of Republic Indonesia for financial support through the Hibah Tim Pascasarjana scheme and for Yayasan Pendidikan Katolik Arnoldus, Universitas Katolik Widya Mandira Kupang, NTT for the Biaya Studi Lanjut relief fund.

\section{References}

1. Joshi S., Bellet T., Banet, A., Robger, L., Turetscheck,C., Risser, R., Golias, J., Yannis, G., Spyropoulou I., Carvalhais, J., Leden, L., Vasek, J., Delhaye, A., Robeboreck, H., Underwood, G., and Humphrey, K., Understanding Risk Taking Behaviour within the Context of PTW Riders, Paris, 2010.

2. Wong, J. T., Chung, Y. S., and Huang, S. H., Determinants behind Young Motorcyclists' Risky Riding Behavior, Accident Analysis and Prevention, 42(1), 2010, pp. 275-281.

3. Chen, C. F. and Chen, C. W., Speeding for Fun? Exploring The Speeding Behavior of Riders of
Heavy Motorcycles using the Theory of Planned Behavior and Psychological Flow Theory, Accident Analysis and Prevention, 43(3), 2011, pp. 983-990.

4. da Costa, D. G. N., Malkhamah, S., and Suparma, L. B., Motorcyclist Risk Taking Behavior, Proceeding of the 19th International Symposium of FSTPT, Islamic University of Indonesia, 1113 October 2016, 2016, pp. 77-85.

5. Knight, P. J., Iverson, D., and Harris, M. F., Early Driving Experience and Influence on Risk Perception in Young Rural People, Accident Analysis and Prevention, 45, 2012, pp. 775-781.

6. WHO, Speed Management: A Road Safety Manual for Decision-Makers and Practitioners, Global Road Safety Partnership, Geneva, Switzerland, 2008.

7. Bartlett, W., Baxter, A., and Robar, N., Motorcycle Braking Test: I.P.T.M. Data through 2006, Accident Reconstruction Journal, 17(4), 2006, pp. 19-21.

8. AASHTO, A Policy on Geometric Design of Highways and Streets, 2011 6th E. Washington DC: American Association of State Highway and Transportation Officials, 2011.

9. da Costa, D. G. N., Malkhamah, S., and Suparma, L. B., A Systematic Approach in Developing an Accident Risk Reduction Scheme, 6th International Annual Engineering Seminar, 2016, pp. 1318.

10. Kokot, D., Rijavec, R., and Ambroz, M., SURF8Kokot-mod, Slovenia, 2012.

11. Malkhamah, S., Tight, M., and Montgomery, F., The Development of an Automatic Method of Safety Monitoring at Pelican Crossing," Accident Analysis and Prevention, 37(5), 2005, pp. 938-946.

12. Lamble, D., Laakso, M., and Summala, H., Detection Thresholds in Car Following Situations and Peripheral Vision: Implications for Positioning of Visually Demanding In-Car Displays, Ergonomics, 42(6), 1999, pp. 807-815.

13. Smith, T., Garet, S., and Cicchino, J., The Effect of Sight Distance Training on the Visual Scanning of Motorcycle Riders: A Preliminary Look, Washington DC, 2013.

14. da Costa, D. G. N., Malkhamah, S., and Suparma, L. B., Pengelolaan Risiko Kecelakaan Lalu Lintas: Cakupan, Indikator, Strategi dan Teknik, Proceeding of the 2nd Symposium of The University Network for Indonesia Infrastructure Development, 2017, pp. 195-203.

15. Winkelbauer, M. and Vavryn, K., Braking Performance of Experienced and Novice Motorcycle Riders - Results of A Field Study, 2015.

16. Malkhamah,S., Suparma, L. B., and da Costa, D. G. N., Accident Risk Management Based on Rider Braking Capability, International Journal of Science, Engineering and Information Technology, special issue on 1st ISTSDC 2017 symposium, in-press. 
17. da Costa, D. G. N., Accident Risk Analysis of Motorcyclist, $15^{\text {th }}$ International Symposium of the Indonesian Inter University Transport Studies Forum, 2012.

18. Susilo,Y. O., Joewono, T. B., and Vandebona, U., Reasons underlying Behaviour of Motorcyclists disregarding Traffic Regulations in Urban Areas of Indonesia, Accident Analysis Preview, 75, 2015.

19. Lacasse, S., Hazard, Reliability and Risk Assessment - Research and Practice for increased Safety, Procceding of the 17th Nordic Geotechnical Meeting NGM 2016, Reykjavik, 25th-28th of May, 2016, pp. 17-42.

20. Schroeder, P., Kostyniuk, L., and Mack, M., 2011 National Survey of Speeding Attitudes and Behaviors,Washington DC, 2013.

21. da Costa, D. G. N., Malkhamah, S., and Suparma, L. B., Faktor Pemicu Persepsi dan Sikap Toleran Pengendara terhadap Risiko Kecelakaan, Jurnal Transportasi, 18(1), 2018, pp 39-48.

22. Santosa, S. P., Mahyuddin A. I., and Sunoto F. G., Anatomy of Injury Severity and Fatality in Indonesian Traffic Accidents, Journal of Engineering and Technological Sciences, 49(3), 2017, pp. 412-422.

23. Ueckermann, A., Wang, D., Oeser, M., and Steinauer, B., Calculation of Skid Resistance from Texture Measurements, Journal of Traffic and Transportation Engineering (English Ed.), 2(1), 2015, pp. 3-16.

24. Constantinou, E., Panayiotou, G., Konstantinou, N., Loutsiou-Ladd, A., and Kapardis, A., Risky and Aggressive Driving in Young Adults: Personality Matters, Accident Analysis Preview, 43(4), 2011, pp. 1323-1331.
25. Bell, R., Glade, T., and Danscheid M., Challenges in Defining Acceptable Risk Levels, RISK21 - Coping with Risks due to Natural Hazards in the 21st Century, 2006, pp. 77-87.

26. DaCoTA, Speed and Speed Management, 2013.

27. Stikar, J., Hoskovec, J., and Smolikova, J., Traffic Accident Analysis and Prevention from the Psychological Standpoint, Studia Psychologica, 50(2), 2008, pp. 217-226.

28. Mihradi, S., Golfianto, H., Mahyudin,A. I., and Dirgantara, T., Head Injury Analysis of Vehicle Occupant in Frontal Crash Simulation: Case Study of ITB 'S Formula SAE Race Car, Journal of Engineering and Technological Sciences, 49(4), 2017, pp. 534-545.

29. Hamidun, R., Kordi, N. E., Endut, I. R., Ishak, S. Z., Faudzi, M., and Yosoff, M., Estimation of Illegal Crossing Accident Risk using Stochastic Petri Nets, Journal of Engineering and Technological Sciences, no. Special Issue on ACEE 2015 Conference, 2015, pp. 81-93.

30. Hurst, L. M., Motorcyclist. a Literature Review and Exploratory Analysis of Fatalities and Serious Injury Collisions in relation to Motorcyclists: Implications for Education, Engineering and Enforcement Initiatives, Plymouth University, Cornwall Council. 2011.

31. Lehmann,B. C. C., Haight, J. M., and Michael, J. H., Effects of Safety Training on Risk Tolerance: An Examination of Male Workers in the Surface Mining Industry, Journal of $S H \& E$ Research, 4(3), 2009, p. 2.

32. Iversen, H., Risk-Taking Attitudes and Risky Driving Behaviour, Transportation Research, 7(3), 2004, pp. 135-150. 